\title{
Transport and Accessibility Challenges Facing the Rural People Living Along Feeder Roads in Ghana
}

\author{
Asafo-Adjei Charles Kwarteng*, Usha Iyer-Raniga, Aranda-Mena Guillermo \\ School of Property, Construction and Project Management, RMIT University, Australia
}

Copyright@ 2018 by authors, all rights reserved. Authors agree that this article remains permanently open access under the terms of the Creative Commons Attribution License 4.0 International License

\begin{abstract}
This paper examines the accessibility and mobility needs of communities living along feeder roads in Ghana. It adopts a qualitative research approach where a total of eighteen (18) expert interviews were undertaken across Ghana from 2015 to 2017. In addition, primary data was collected by conducting five focus group discussions in five rural communities in two regions in Ghana. In all, a total of seventy-two (72) participants were involved during the focus group discussions. The study first found that Ghana has enough feeder roads as compared to other countries in the sub-region. From the responses, what needs to be done is to improve the level of services. This means that there is the need to improve the surface conditions and make sure that a lot of them are in good shape all year round. The responses gathered point to the fact that most rural or feeder roads are not appraised before their construction, and that may account for the reason why transport investments are not factored into the plan of most feeder roads. It is interesting to note that most of the roads that were appraised were either funded by donor partners or development partners other than government institutions and the models used do not place much premium on transport vehicles. It was again found that adoption of Intermediate Means of Transport (IMT) on a rural road is a good policy provided it is very cheap, economical, affordable and user- friendly. The challenges revealed by the respondents regarding the accessibility and mobility were not quite different from past studies. Challenges revealed include poor or low-quality equipment, poor paths or roads, lack of consumer appeal, the high cost of acquisition, and access to finance. It is recommended that the only way transport services can be considered in the development of rural road infrastructure is when the Ministries for Roads and Transport collaborate effectively.
\end{abstract}

Keywords Accessibility, Ghana, Mobility, Transport, and Rural

\section{Introduction}

The focus of Ministries of Transport across Africa and some developing countries has been on road construction and maintenance even though good transport systems depend not only on road infrastructure. An effective transport system depends on roads and appropriate vehicles which should be available in the right place and time [1]. Poor access affects the cost of living and life in the general well-being of the people involved. In most African countries, transport services are provided by small operators, a situation, which to some extent influences the quality of the services. Indeed, transportation in the rural areas, for example, tends to be expensive, unsafe, crowded due to lack of competition [2].

The lack of efficient transport on feeder roads in Ghana results in situations where many of the road users are not able to access health, economic, educational and other social needs. Reasons adduced for this worrying situation are quite puzzling. Many have proposed the use of Intermediate Means of Transport and have wondered why its use has not been readily patronised in sub-Saharan Africa, just as they have been accepted in certain parts of Asia.

Others have also attributed transport inefficiencies to issues like poverty, lack of regulation of transport operators, lack of adequate policies, the inadequacy of transport appraisal methodologies, the influence of Funding Agencies and other Developing Partners. Concerns have been raised by institutions like the Asian Development Bank, as to why resources should be expended on the construction of roads if there will be no guarantee of traffic that meet the very purpose the roads are constructed [3]. Road connectivity and transportation plays a significant role in the development of rural communities along feeder roads. These feeder roads expose most of these rural communities to regional or urban centres which are very vital for economic growth development $[4,5,6,7]$. There seems to be a growing bias, particularly in developing countries, in the area of research regarding rural roads accessibility. It is interesting to note that there is limited studies on rural mobility issues or challenges particularly in Africa making a lot more people vulnerable and poor [8, 9]. It is therefore important for contemporary research to focus on addressing these gaps in the literature. This study 
focuses on the opinions of in-Country Feeder Road Experts on accessibility and mobility issues during the design of feeder roads in Ghana. The study delves into the factors that influence the type of interventions they adopt during the appraisal of transport projects, as well as the contribution of IMTs in the absence of conventional transport system.

\section{Background}

Ghana is a developing country which gained middle-income status statistically in recent years. The Country discovered oil in large commercial quantities in 2007. It was anticipated that the discovery of oil would have catapulted the economy into higher levels of national income and bring into the Country needed resources to address its poverty and other challenges.

Despite the high expectations of many Ghanaians, Ghana is currently battling with frequent cuts in the supply of electric power, which is crippling the economy. The lack of adequate energy for industry and domestic consumption is one challenge facing the ordinary Ghanaian. This phenomenon has been christened "dumsor" in one of the popular Ghanaian languages. The unmet demand has increased so much that its effect is felt in the whole country to the extent that the term "dumsor" has gained international meaning. Discussions given on the inadequate and irregular supply of electric energy by the Ghanaian media, the need for an increase in the electric energy appeared to be the most critical problem facing the Ghanaian economy and thus receiving more attention from the Government. This crippling energy crisis facing the Country has relegated the diverse pressing needs of the citizenry to the background thus overshadowing the development of other sectors of the economy.

The population of Ghana is reported to have increased from six million since independence in1957 to about twenty-nine million by the end of 2018 [10].

The major problem facing the Ghana transport industry is because the supply of transport infrastructure is in short supply and of poor quality. The provision of road infrastructure has been a major component in the development agenda of Ghana and took about a third of the infrastructure budget. The principal mode of public transport in Ghana is by road; this is because the road transport carries $94 \%$ of the internal freight movement and $97 \%$ of all passenger traffic in Ghana. Only about 6\% of freight and 3\% of passenger traffic are conveyed by other modes like rail and inland water transport [11]. Ghana has a planned road network estimated to be 74,000 kilometres as at the end of 2017, most parts of the road network are not accessible during the rainy seasons and require provisions of structures like surface pavement, culverts and bridges to make them passable in all seasons. The $74,000 \mathrm{Km}$ of the national road network comprises of trunk roads, urban roads and feeder roads. The feeder roads networks are more than half of the total road network. These feeder roads link more significant parts of the rural communities where the majority of the population lives. In most of these rural areas, accessing transport services are major problems, and the lack of suitable transport systems hinder smooth movement of the goods and services.

The interventions from Government in the past have been focused on the provision of road infrastructure, and the attention of Government had been to improve the road infrastructure needs of the country. The ability to meet this challenge facing the country is a major political issue which has a significant influence on the electorates' decision especially in rural areas where the need for all weather accessibility is very high. The decision to provide road infrastructure which is now political has led to the demand for transport services being relegated to the background. The rising population gives credence to the fact that the demand for transport is going to be increasing and the pressure on transport infrastructure and services will increase correspondingly.

However, besides electricity, the Country is in dire need of infrastructures like roads, hospitals, telecommunication, water and housing. Ghana will need a continuous massive investment in infrastructure if the vision of making Ghana the transport hub of the West African Sub- Region is to be realised. This vision entails the country investing in the transport infrastructure. The internal transport in Ghana for people and goods is about $98 \%$ by road. The demand for mobility across the country to address the transport needs is very high and tends to put political pressure on the Government as all areas of the country call for an equal share of the national income for infrastructure development. The limited resources place the Government in unplanned development and expenditure resulting in high budget deficits in an attempt to address the gaps in infrastructure.

\section{Literature Review}

The terms "accessibility" and "mobility" has been widely used in many kinds of literature with varying contextual meaning. Accessibility may be defined as the ease a facility or place can be reached from another location. While the emphasis on Accessibility is on the "ease", the focus of Mobility is on the "ability". Thus mobility places a premium on being able to move from one place to the other, that is, having the capacity to move from one place to the other. Perhaps a clearer description of accessibility has been provided by the Social Exclusive Unit of England (SEU). SEU sees accessibility as the ease of getting 'key services at a reasonable cost in a reasonable time'. From the views of SEU, accessibility can be gauged by the existence of transport between the people and the service, the awareness of the transport service by the people. Also, one has to check if the transport service is 
reliable, safe and trusted by the people. SEU is of the opinion that providing transport is not enough without locating the services at places where it is reachable financially and physically [12]. The ability to reach basic services with ease is quite crucial for the improvement of the livelihoods of the rural dwellers in Ghana. There is, therefore, the need to probe the absence of access and mobility to the basic needs of life in the rural areas.

All over the World, Infrastructure developments are seen as the basic foundation for the development of the economy for industrialisation to take off. As most economies of Developing Countries in the West African Sub Region depend on agriculture and raw materials, investment in infrastructure development becomes a key component in their desires to address poverty [13]. Accessibility and mobility largely depend on the availability of transport infrastructure. Lack of adequate infrastructure hinders access to the necessities of life. Infrastructure development provides the critical support for a country's economic development [14, 15]. Many countries face a daunting task with apportioning limited resources to meet the high demand for the development of energy, water, and housing infrastructure which are vital for the growth of their economies.

A country with sound infrastructural can attract investment growth and expansion of its economy as it becomes very attractive for further investment. Transport infrastructure has been in demand for many Developing Countries; there is the need for new construction and the maintenance of the existing roads. Lack of road access deprives many people of access to educational, health care and other economic activities and services. Poor transport infrastructure has contributed to many deaths, for this reason, transport needs became major discussions for consideration under the United Nations post-2015 agenda setting [16].

A sound investment in the transport infrastructure and services contributes to economic growth. Transport infrastructure, for example, is a key to tourism development. There is enough evidence that countries with a high level of investment in transport infrastructure have a comparatively high volume of trade. Generally, high investment in transport infrastructure also leads to lower transport cost $[17,18]$. Infrastructure availability influences decisions made by individuals, households and entrepreneurs. The cost of transport, for instance, serves as incentives for firms and individuals to locate or relocation activities to given places. Transport is a necessary input for wealth creation and transformation of economies from lower income levels to higher ones.

Transport services in Africa are still provided by small private sector operators who cannot deliver to the expectations of the people. These unsatisfactory services tend to impact negatively on the activities of poor farmers with under-developed markets and poor infrastructure. Interestingly transport in these areas tends to be expensive and unsafe for the people with little or no competition [2]. Over the years, the call for Transport Planning in Africa has been enormous, particularly in the last two decades. Several studies and reviews have called for a concerted effort in examining the issue of mobility and proximity, not merely focusing on transport. This has been supported by studies conducted by the International Labour Organization (ILO) and the World Bank's Sub-Saharan Africa Transport Policy Program (SSATP). These studies have called for tools such as Integrated Rural Accessibility Planning (IRAP) and Accessibility Planning (AP) as a way of understanding the challenges faced by rural folks and how to set achievable priorities [19] Other tools, such as the Sustainable Livelihoods Approach, have also been used extensively in Transport Planning studies [8, 9]. For example, Bryce son et al. [9] used this framework in the assessing the social and economic benefits of mobility. The study by Bryce son et al. [9] on Zimbabwe and Uganda found that mobility varies with income and therefore the poor tend to rely on non-motorized transport, unlike other income groups. On the other hand, high and medium-income groups tend to like motorised transport. This implies that there is the need to strengthen non-motorized transport for the benefit of the poor in the short term while other interventions are used to increase their incomes to address the inequality.

\section{Addressing Rural Transportation Services}

IMTs provide solutions to the numerous transportation challenges faced by people to reduce labour cost associated with transport [2]. They are seen as intermediate because they are between human walking and large-scale transport. IMTs can improve transport of both small and medium loads which may be a bit difficult for human beings to carry. The recognition of the potentials of IMTs in Sub-Saharan Africa was discovered in the 1980's even though it is only in recent times that research and development have been enormous [2]. The dominant IMTs identified in the late 1980's include bicycles, tricycles, ox-carts and water carriers. IMTs have been adopted extensively in Asia. It is yet to make a similar impact in Africa due to differences in population density, income levels, industrial base, taxation and cultural factors [20]. For example, Gauthier and Hook [21] have found that the differences in the adoption of IMTs in Kenya and Zambia can be attributed to their taxation regimes. Whereas Kenya's reduced tax is positively affecting the adoption of IMTs, Zambia's tax system is creating a serious impediment in terms of adoption. As earlier indicated, most people in rural areas do not have the means to own a car, and therefore mobility is synonymous to walking or IMTs or, better still, public transport. Transport services in most rural settings along feeder roads are delivered by way of animal-drawn carts, 
bicycles, motorcycles, tricycles or taxis. These are the main transport for rural in most countries. An interesting observation is that IMT as a means of transport is often ignored even though it plays a critical role in the mobility of rural people. While providing access to markets, healthcare and educational facilities, IMTs also provide employment for the operators [22; 23, 24; 25; 26].

Unfortunately, most government officials in Africa look down on IMTs as means of addressing the transportation problems facing rural people [2]. IMTs are not new in Africa. Several countries such as Angola, Ghana, Kenya, Nigeria, Uganda, Zambia and others have attempted to adopt them, even though they have been confronted with numerous challenges. Some of these challenges include poor or low-quality equipment, poor paths or roads, lack of consumer appeal, the high cost of acquisition, and access to finance. For example, the provision of poor or low-quality equipment has been a very significant challenge for most of these countries, especially Ghana. Most of the equipment provided for the implementation of the Village Infrastructure Projects was all inappropriate [22; 27]. Currently, the bicycles and the motorcycles are imported from Asia. China and India seem to be making headway as far as the introduction or adoption of IMTs is concerned. The assumption underlying the construction of roads in developing countries is that if roads are constructed, automatically the private sector will take advantage by developing transport services along the road. This continues to be a failure as in most cases the roads have been built, but only a few people are utilising them since there are no conventional transportation systems. It is important for governments in developing countries to look for innovative ways of addressing the transport challenges facing the rural people through proper and effective planning which has hitherto not been the case.

\section{Research Methodology}

The research Methodology provides step-by-step information about how research is conducted. Since the study is about peoples' opinions, perceptions and the quality of services relating to mobility and accessibility, the application of Qualitative Methods appeared to be more appropriate, and therefore the study adopts a Qualitative Research Approach. The reason for adopting a qualitative approach was the fact that the researcher sought to collect answers to open-ended questions with the intent of understanding the problem from Ghanaian perspectives as a contribution to literature. Cresswell [28] believes that a qualitative approach is the one where the researcher gathers information from multiple perspectives, with the view of developing a pattern which can explain a particular phenomenon. Qualitative approaches enable researchers to ask probing questions. The research participants are offered the flexibility and an opportunity to freely express themselves with the hope of addressing the study objectives.

The data used was collected from both primary and secondary sources. The primary data was collected through in-depth interviews. Using the expert interview to seek information from experts at the exploratory stage of research offers the opportunity to elicit and access information from individuals, organisations and institutions which may be ordinary difficulty to have using other qualitative methods or techniques [29]. According to Bogner, Littig and Menz [29], it is a quick way of gathering data as expert interviews, provided there are enough motivations for experts to participate and share their experiences. An enabling environment is often created if the interviewers and the experts have related or common professional backgrounds or experiences. Expert interviews serve as focal points to have concentrated data from the people by their experience and knowledge from positions they occupy or have occupied. It is relatively less expensive to use the formal structures like secretaries of experts to gain access to them. Where some experts are interested in the topic, they offer wider information and may make a recommendation to reach their colleagues in their network or cycle of experts. Contributions from experts are generally perceived as legitimate and serve as good motivation to gather more information in areas under the study. The interview questions were carefully crafted to cover the thematic areas of the study.

The respondents for this study were purposively selected by the positions they occupy in their organisations and the fact that the play varying roles in feeder roads construction and maintenance. Purposive sampling technique has been useful for this study because of the control it offers the researcher in selecting appropriate cases for the study. In order to make good use of the data collected, the recorded interviews from the field were transcribed for easy coding and further analysis. The data gathered from the interviews were analysed using Nvivo 12 Plus. The data were coded according to the core themes of the research after which the discussions followed.

\section{Analysis and Discussion of Findings}

The analysis was organised along five main themes namely;

- Feeder roads construction and maintenance,

- Types of vehicles on rural roads,

- Intermediate means of transport, transport appraisal models, and

- Users' benefits associated with improvement in their accessibility and mobility

- Accessibility and mobility challenges as presented in figure 1 attached. 


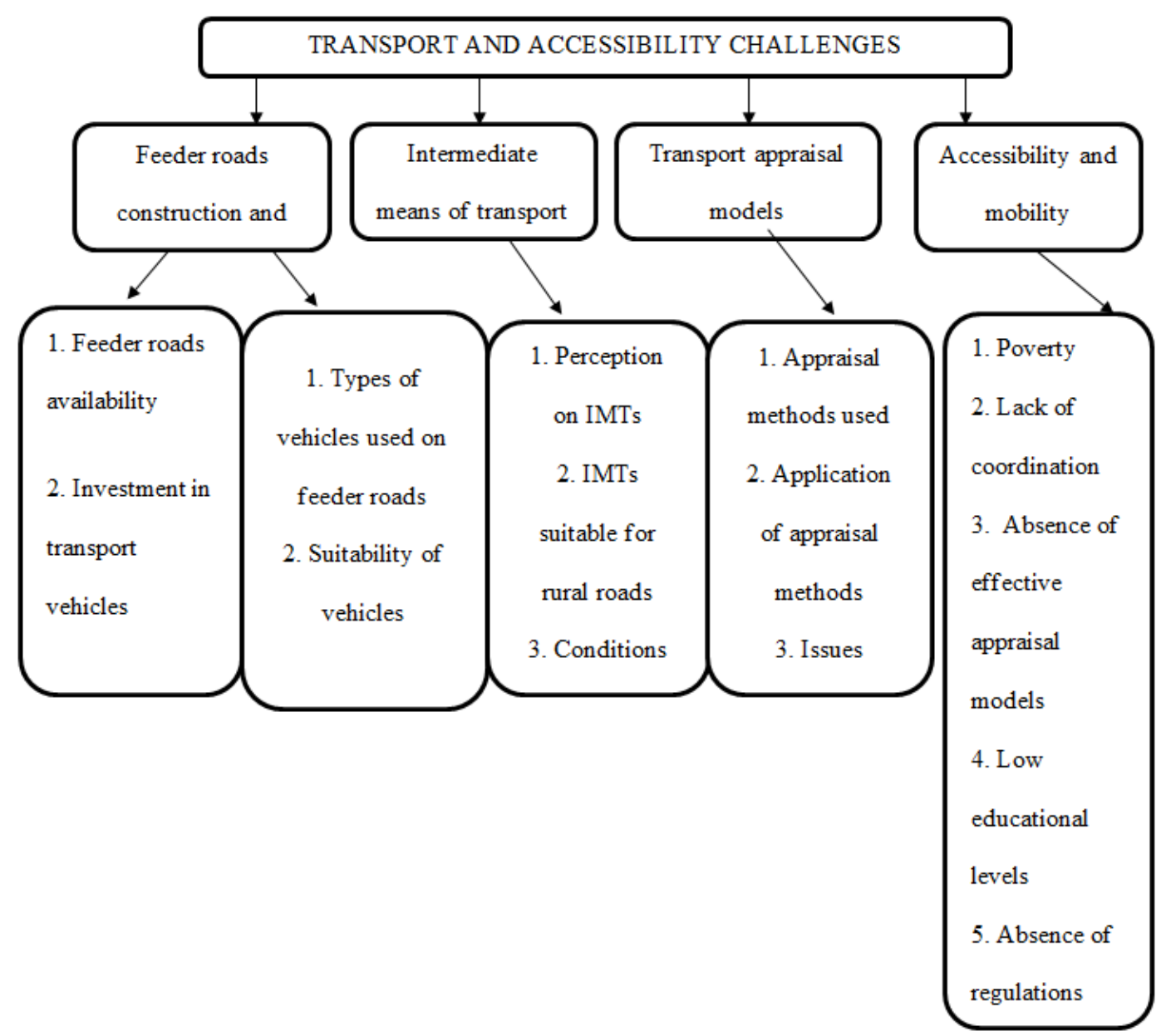

Figure 1. Major analysis themes and sub issues

\section{Feeder Roads Construction and Maintenance}

In this section, key issues that will be discussed include the availability of feeder roads, investment in transport vehicles and rural transport responsibility. Related issues include the types of vehicles used on feeder roads and the suitability thereof. The study first sought to determine whether or not Ghana has constructed enough feeder roads. Most of the respondents indicated that looking at the landscape of Ghana; enough feeder roads have been constructed. A respondent revealed that:

"I think so because if you look at the feeder road network (4200km plus) and you look at the land area of Ghana and you look at the connectivity, and you compare that to counties in sub-Saharan Africa, you will realise that we have done enough".

In addition, a respondent added that: "I think the number of roads we have in Ghana is enough, it is okay. Maybe we need to intensify our efforts on the maintenance of those existing roads".

From these categories of respondents, what needs to be done is to improve the level of service which means there is the need to improve the condition and make sure that many roads are in good shape all year round. According to these respondents, once this is done, the country will be on its way to meet its transport needs. On the other hand, some respondents were of the view that there is still more to be done. For instance, a respondent stated "Not at all, there are still more to explore, and even some of the communities are expanding. It is like more paths are being created which the people are expecting the government to develop them into proper engineered roads. We still have a long way to go".

Another respondent hinted that there is the need to construct more roads provided funds be made available. This is what he had to say "In fact, there is a need to construct more but based on the availability of funds. I think it would be prudent for us to concentrate on the maintenance of the existing ones because we have about $42000 \mathrm{~km}$ of feeder roads". These respondents believe that most of the rural roads networks are not engineered, and therefore they need to continuously maintain or upgrade them to make them motorable all year round. It is expected that every engineered road should see some minimum maintenance during the year. This tells the extent to which new roads should be constructed or the old ones 
maintained.

The responses gathered point to the fact that most rural or feeder roads are not appraised thoroughly before their construction and that accounts for the reason why transport investments are not factored into the plan of most feeder roads. It is interesting to note that most of the roads that were appraised were either funded by donor partners or other development partners other than government institutions. Actually, for most of these agencies, Project Appraisal is a strong requirement if the project is to see the light of day. Highlighting how relevant Project Appraisal is though it is not often considered, an interviewee had this to share:

"Well, we try to do that, but under the RTTP (Rural Travel and Transport Program) funded by the World Bank, we were forced to do that. RTTP is a World Bank initiative that the Department of Feeder Roads took part and then we tried to look at both transport infrastructure and services. Under the current arrangements, the Ministry of Roads deals with road infrastructure, and the Ministry of Transport deals with transport services. So as you know, we are supposed to liaise closely, but I do not think we have done that in the past".

It is instructive to note from the above responses that the only way transport services can be considered in the development of rural roads is when the Ministries of Roads and Transport collaborate effectively. The results of some Department of Feeder Roads projects sponsored by the World Bank, which aimed at promoting non-motorized transport services on rural networks in the Northern part of Ghana, showed that given a chance, non-motorized transport would at least provide some transport services on the rural network. It is generally assumed that if rural roads network is upgraded or developed, automatically people living along the roads will stop head-loading and transfer to motorised transport which is not the case always. This is because most of them do not have the means to take advantage of the opportunities provided by these road expansion projects. This means that they have to move slightly to non-motorized transport, raise their income levels before transferring it to motorised transport but you need something to break that inertia. There is the need for some subsidised services because urban transport is subsidised, but rural transport is not. Providing funding for people to buy non-motorized transport or subsidies will be in the right direction. It is clear that the Ministry of Transport is responsible for service, so it means the Ministry of Roads provides infrastructure. Interestingly, some respondents also felt that the Department of Feeder Roads should focus on the construction and leave out the transport issue to other agencies under the Transport Ministry.

Respondents were also asked to indicate whether or not there are specific types of vehicles that are suitable for rural roads. Some of the respondents responded positively because not all vehicles are suitable. A respondent revealed that "Well, think 'yes"' of course, but this will differ from area to area, e.g. when you go to the northern sector you will see many people using bicycles, motor bicycles, donkeys, and few motor vehicles but if you come to Southern sector it's mostly motor vehicles, few bicycles and motorized tricycles".

In support of the above, a respondent added that: "I do not think there is any specific vehicle that would be suitable for the movement of goods on our feeder roads based on the types of feeder roads they are talking about. Because if it is a tarred road, I think all can pass on it, but if it is a rough road then I think four-wheel drives and pick-ups would be preferable during the rainy season than maybe a bus or van or whatever it is".

This implies that, to some extent, the nature of the road and the weather conditions determine the kind of vehicles that can play a particular route at a point in time. Most of the respondents also believe that the promotion and development of road transport services should be the role of the Private Sector because Government or Public Sector organisations have not performed so well when it comes to transport services. According to one of the respondents:

"In Ghana, when it comes to transport, it is the private people who normally go into it. So I do not know if we still want Government to be involved, which to me ..... We have had some experience before. These Omnibus Service Authority (OSA)' buses some years back were mismanaged, and because of that, I would prefer private people to go into transport services and leave Government out of it. Seriously, I do not see the role of Government in there".

It is therefore not surprising that transport services are mostly relegated to the background when discussing the development and maintenance of Rural or Feeder roads in Ghana. Generally, most of the people at the helm of affairs believe transport services should be the role of the private sector no matter what. This confirms the assertion made by previous studies particularly in Africa where the private sector provides the majority of transport services.

\section{Intermediate Means of Transport (IMT)}

Considering the economic conditions in most rural settings in Ghana, there are calls for the introduction of intermediate means of transport which can reduce some of the challenges associated with transport along feeder roads. This section, therefore, looks at respondents' perception on IMTs, IMTs suitable for rural roads and the conditions for IMT adoption in Ghana. IMTs are generally seen as anything between walking and relatively large-scale motorised transport. 
On the role and use of IMTs, a respondent indicated that:

"IMTs are for short distance. They are most appropriate to use because you do not need to get a certain number of people. In terms of short distance, IMTs are needed. Eventually, IMTs are used for commercial purposes. Therefore, I see IMTs as good transport system on rural roads to carry goods".

A respondent also said: "IMTs can serve several purposes as it can even be used in times of emergency. Some communities I have visited use IMTs for emergency services. From my experience, I feel it will be useful for the rural community. They can be used to carry goods, children, and other passengers."

On the issue of IMT suitability, some respondents indicated that IMTs are suitable in communities where conventional transport systems are ineffective or absent. To these respondents, the suitability depends on the availability of other forms of transport as well as the nature of the road network. A respondent reiterated that: "In communities where they have no commercial means such as buses and taxis, IMTs can be used as a means of transport for both human beings and goods. They can serve emergency purposes. I am saying this because it is used to convey pregnant women in the rural areas".

Adding his voice to the above, a respondent illustrated how IMTs could be beneficial in the fight against poverty in rural areas. He shared this:

"To the rural folks, carrying the foodstuffs from the farming gate to the market centres is their aim, and it is not the means. In view of that whether it is bicycles, tri-cycles or donkeys; the most important thing is that it relieves the hardship of the rural folks. So instead of carrying it on the head, these non-motorised means will help. It saves them much time".

According to the responses, IMTs have been adopted in several African countries which imply that Ghana can also adopt them provided the right framework or policy is developed. Respondents see the adoption of IMTs on a rural road as a good policy on account of being very cheap, economical, affordable and user-friendly. In the absence of the conventional vehicle (like buses, taxi, etc.), IMTs can be used as the main vehicle on rural roads. All these can be achieved if road planning considers transport as well. Roads are meant for movement of goods and services using vehicles, so there is the need to investigate the type of vehicle the road for which the road is intended.

Asked why IMTs are not making the necessary impact in Ghana, respondents indicated some challenges confronting the promotion and subsequent adoption. A respondent shared that: "Even though the cost of acquisition is not high as compared to motorised transport, there is the need for subsidies to be provided because a lot of them cannot afford to buy on their own. Loan schemes such as MASLOC (Microfinance and Small Loans Centre) can contribute in this arena".

Another respondent indicated that quality of equipment in the market and poor nature of some of the roads are also affecting the adoption of IMTs. He indicated that "most of the supporting equipment is of inferior quality and therefore it does not last. Again most of the rural paths or roads are in bad shape such that donkeys or other animals will struggle to ply".

Some respondents were quick to add that culture is playing a key role in the adoption and promotion of IMTs in Ghana. The adoption rate in the Northern part of Ghana is higher than the southern part primarily because the northerners are used to them. On the other hand, southerners prefer motorised transport to IMTs. A conscious effort at creating the needed awareness of its importance will be most appropriate for the entire country.

\section{Transport Appraisal Models}

It was important also to determine whether feeder roads projects are appraised to determine their viability. The responses show that the issue of viability does not matter because several factors other than viability are considered. An interviewee hinted:

"When we started Feeder Road Department, it was clear that communities were coming with their request and we were following up and developing them. We did that for a reasonable time of over 10 years. However, since my assumption of duty, I have seen that the politics of today influence this matter".

Indeed most of the respondents see the selection routes to be more political rather than technical. This implies that even if the appraisal shows that it is not viable, there are no way politicians will allow it to hold. A respondent retorted:

"As at now, selection of roads is not even done by the technical men here. The politicians do it. They bring their list and ask you to go and carry out your studies. So whether the study is good or bad, you have to carry out the instructions of politicians”.

The responses show that Appraisal Models are not used most often even though their use can positively impact on the success of projects. Asked the dominant model used, a respondent stated:

"I think we use the Internal Rate of Return (IRR) because what we do is to look at "before" and "after". That is the situation before the road was constructed and when the road was constructed; what is the effect? Has it increase the output of food crops from the rural areas; what about lifestyle; has it been improved?"

In reality, the appraisal models are supposed to provide some technical evidence for the decision made, but unfortunately, it is not the case. This accounts for the 
absence of appraisal models in Government of Ghana funded road projects because the outcome of the appraisal cannot change the decision.

\section{Accessibility and Mobility Challenges}

Road Transport Planning and implementation has faced some challenges over the years.

This section analyses the challenges facing rural transport accessibility. Some of the challenges identified include

- Absence of effective appraisal models or tools,

- Low educational levels,

- Lack of political commitment,

- Absence of regulations and others.

On the issue of the challenges, some respondents indicated that poverty is the biggest challenge as it is the reason why most rural people cannot afford some forms of motorised transport and therefore had to resort to other means. An interviewee shared his thoughts:

"Many people resort to the use of motorised tri-cycles, especially in the South, because they either have no option or they cannot afford the other options', and these tri-cycles and motor-bikes are playing the role of taxis without obeying the rules and regulations".

The actions or inactions have made tri-cycles or motorbikes very dangerous for people living along feeder roads in Ghana because of frequent accidents and claims innocent lives. Another respondent added his voice:

"I am not against it, but it has serious accident rate. The people need to be educated very well because, we often hear a lot of accidents by this tricycle, and in the night when you meet them, they appear like motorbikes because the whole body is not portrayed for on-coming vehicle or any pedestrian to know that what is coming is not just a motor bicycle but a tricycle. So, before you realise either it has knocked down a pedestrian or collided with an oncoming vehicle, and this can be disastrous. There have been many accidents. So there has to be more education, and maybe they need to put some light at the edges, so that, it can indicate or show the sides of the tri-cycle coming. In the night, you cannot identify it very easily, unless it gets closer to you".

The responses show that lack of coordination is one of the key challenges affecting accessibility and mobility in rural Ghana. A respondent bemoaned how lack of coordination has affected Road Design, Maintenance and Planning in Ghana.

"Coordination is very important because I think that, there shouldn't have been any separation; the
Transport Ministry and the Road and Highways should be one Ministry. In that case, we would have been able to address that issue and even design roads for specific means of transport because, though we talk to each other, I do not think it has been easy".

The challenges revealed by the respondents regarding the accessibility and mobility were not quite different from past studies. Challenges such as poor or low-quality equipment, poor paths or roads, lack of consumer appeal, the high cost of acquisition, and access to finance. These have been confirmed by Porter [22] and Porter and Lyon [27]. Africa still relies on the Private Sector for Transport services though the Private Sector Transport Services operators do not have the capacity to deliver that mandate given the economic conditions in most of these countries.

Same can be said of Ghana as Transport Services are left in the hands of the small Private Sector operators. Most of these operators exploit the rural poor in their bid to provide these services. From the responses, it is pretty clear that the services rendered are unsatisfactory and impact negatively on the activities of poor farmers with under-developed markets and poor infrastructure. The transport provided by these operators is expensive and unsafe. The responses above call for concerted efforts in examining the issue of mobility and proximity not merely focusing on transport.

The responses show that given the necessary attention, rural transport can contribute significantly to the fight against poverty in rural Ghana. This has been supported by studies conducted by the International Labor Organization (ILO) and the World Bank's Sub-Saharan Africa Transport Policy Program (SSATP). These studies have called for tools such as Integrated Rural Accessibility Planning (IRAP) and Accessibility Planning (AP) as a way of understanding the challenges faced by rural folks and how to set achievable priorities [19, 30]. Generally high and middle income groups tend to like motorised transport. This implies that there is the need to strengthen motorised transport for the benefit of the poor.

What is a bit difficult to comprehend is the fact that the Private Sector is considered the engine of growth in Ghana and yet it is unable to deliver transport services in the rural area in Ghana effectively. This raises a serious question that needs to be answered. It looks like the absence of a comprehensive Appraisal Models that take into consideration the needs of people living along the feeder roads in the planning and implementation of rural roads projects and programmes is accounting for this failure. The responses show that the selection of feeder roads is mostly a political decision which normally fails to incorporate any technical decisions. Lack of coordination mentioned as one of the key challenges could be the reason why the Private Sector is failing in this regard.

The responses on the adoption of IMTs are not surprising as previous studies have confirmed the extent to which countries in Sub-Saharan Africa have adopted IMTs as a reliable means of transport both for goods and human 
beings. From the study, the dominant IMTs include bicycles, tricycles, donkey-carts and water carriers even though it is yet to receive the full attention it deserves. The findings confirm the view held by scholars such as Ellis [20], Starkey, [2] and Gauthier and Hook [21] that IMTs are very popular in Asia, unlike Africa, primarily due to the differences in population density, income levels, industrial base, taxation and cultural factors. Most people in rural areas do not have the means to own a motorised transport, and therefore mobility is synonymous with walking. Transport services in most rural settings along feeder roads can be improved by resorting to the help of animal-drawn carts, water carriers and others, especially where conventional transport systems are absent. Despite the significant contributions of IMTs to rural transport in the world over, it is yet to make such impact in Ghana.

\section{Users' Benefits Associated with Improvement in their Accessibility and Mobility}

Most of the respondents were of the view that the construction and maintenance of feeder roads are very important to them due to the transfer of agricultural goods from the farmlands to the market areas. They added that construction of roads pave the way for vehicular movement of goods and services from one community to another community and allow drivers of vehicles to make prices affordable to the rural community dwellers. One respondent said that when roads are constructed, it reduces rural-urban migration.

They, however, indicated that there is the need to plan to ensure that the type of vehicle recommended using the feeder roads, do so to ensure that the roads are not destroyed by heavy loads. "Now, we have access to vehicles at any time of the day which has helped in making movement easier. Hitherto, it was very difficult to get access to a vehicle as most drivers did not want to ply the road due to its bad state.

Again, before, immediately there is an increase in petroleum prices, drivers increase the fare prices. They attribute the increase to the bad nature of the road. However, they hardly increase fare prices even if there is an increase in petroleum prices now". "Yes, feeder roads are important as they are needed to transport agricultural produce", he added.

The feedback from the respondent also indicated that once the roads are constructed and maintained the number of the vehicle would automatically increase and this will support the people in terms of health delivery and access to agricultural inputs and markets. This is because they attributed the successful marketing of foodstuff to the availability of adequate transport.

However, they were of the view that as long as the roads remain poor, the vehicle's maintenance always compels drivers to increase transport fares which is a major challenge. Also, the respondents were of the view that demand for particular vehicles depends on the type of roads available to the communities.

Another respondent, an expert from the Feeder roads said that transportation process is always considered when initiating any road policy, estimating the number of the vehicle as well as the type of vehicles expected to ply on the road to open up these places for economic activities. In doing so, the transportation system brings about the influx of vehicles to help develop the area through the provision of social amenities.

"Before the construction of the road, drivers complained about the cost of maintaining their vehicles due to the nature of the road. As such, the increment in transport fares was quite regular. With the construction of the road, the situation has changed. Revenue accrued by the district assembly was low. This was because the bad nature of the road prevented people from coming to the market in Ofuman. The traders and farmers then are unable to sell more and pay the appropriate tax to the assembly. The construction of the road has helped in the delivery of healthcare. Again, it has made it possible for more vehicles to assess the community. This community is farming dominated one. Due to the bad nature of the road, some of the farms produce decay at the farms as transporting them to the main township is difficult". (An Expert)

"Yes, the essence of constructing roads in rural areas is to reduce poverty in these areas. As such, in constructing roads, it is important to provide means of transportation as without transport means; it would not be possible to transport foodstuff from the rural area to urban centres. So as much as we are concentrating on the road, we also have to be thinking about the type of vehicle". He added

\section{Conclusions}

From the study, it was gathered that the provision of Transport Service should be in the realm of the Private Sector but supported by appropriate policies and regulations from the Government. Respondents also gave a good indication about the type of vehicles used on rural roads or suitable for rural roads. IMTs are generally seen as good because they are cheaper to acquire, economical and user-friendly. However, when it comes to the motorbikes, the concern is that the safety aspect should be important. In a motorcycle, we should be careful in the distinction between the motorised tricycle and the other ones. All over the world, many of the world's poor live in rural areas; these people lack basic infrastructure such as Roads, Healthcare, Markets and Education as well as transport services. The absence of effective transport services to these people comes with enormous challenges.

The finding of the study has shown that IMTs are assuming significant roles in developing countries such as 
Ghana where it is playing a very significant role in the lives of the rural poor. Respondents believe IMTs are appropriate because it can be used anytime and can be used for commercial purposes in some cases. It is pretty clear that IMTs provident significant benefit to the rural from transportation of goods to improving human health. This implies that IMTs are very relevant and supportive to communities in the hinterlands. In the absence of conventional vehicles, emergency services situations like carrying patients in critical condition, most rural poor communities resort to innovative approach using bicycles, pedicabs and other IMTs to provide these essential services. It is also worthy to note that the adoption rate varies depending on the location of the country. For example, the adoption rate in the Northern part of Ghana is higher than the Southern part primarily because the northerners are used to them. On the other hand, IMTs are not common in the southern part because the people prefer motorised transport to IMTs primarily as a result of their cultural orientation. Most people prefer motorised transport because it is fast and it carries many goods, and it requires little human efforts as compared to IMTs.

In the past, very little attention has been paid to studies on the implications of transport investment in rural areas. Good roads can stimulate development, but road investment alone cannot bring about the needed development. This is because the poor may not be able to take advantage of the opportunities provided by good roads network. There is strong evidence to back the fact that good rural roads provide numerous economic and social benefits to surrounding communities which hitherto were lacking. Studies from countries such as Ghana, Ethiopia, Uganda, Bangladesh, India, Nepal, Pakistan, Morocco, Vietnam, China and others show that the upgrading of even footpaths to motorable roads has positive impacts on the rural poor. It can, therefore, be concluded that Governments and all other stakeholders should be concerned with transport services along feeder roads while giving their attention to other equally demanding infrastructure needs in order to bring qualitative change to the lives of the rural poor.

\section{REFERENCES}

[1] Ellis S, Hine J. The transition from non-motorised to motorised modes of transport. In7th World Congress on Transport Research, Sydney 1995 Jul.

[2] Starkey P. Local Transport Solutions--People, Paradoxes and Progress: Lessons Arising from the Spread of Intermediate Means of Transport. World Bank, Washington, SSATP Working Paper, 2001

[3] Hettige $\mathrm{H}$. When do rural roads benefit the poor and how? An in-depth analysis based on case studies. Asian Development Bank; 2006 Jun 30.

[4] Amos P. Safe, clean, and affordable... transport for development: the World Bank Group's transport business strategy for 2008-2012.

[5] Chakwizira J, Nhemachena C, Mashiri M. Connecting transport, agriculture and rural development: experiences from Mhlontlo Local municipality integrated infrastructure atlas., 2010

[6] Chakwizira J, Nhemachena C, Dube S, Maponya G. Rural travel and disability in Leroro and Moremela villages, South Africa, 2010.

[7] Chakwizira J, Mashiri M. Rural Transport and Freight Governance Crossroads in South Africa. In Abstracts of the 31st Southern African Transport Conference (SATC 2012) 2012 Jul (Vol. 9, p. 12).

[8] Sohail M, Maunder DA, Miles DW. Managing public transport in developing countries: Stakeholder perspectives in Dar es Salaam and Faisalabad. International Journal of Transport Management. 2004 Jan 1; 2(3-4):149-60.

[9] Bryceson DF, Bradbury A, Bradbury T. Roads to poverty reduction? Exploring rural roads' impact on mobility in Africa and Asia. Development Policy Review. 2008 Jul; 26(4):459-82.

[10] Ghana Statistical service Web, 2018

[11] Tryzno P, Applicability of Telecommunications and Road Charges on Traffic Congestion in Accra. Stockholm: s.n., 2004

[12] Social Exclusion Unit, Making the connections: final report on transport and social exclusion. http://webarchive. national archives. gov. uk/+/http://www. Cabinet office. gov. UK/media/cabinet office/social_exclusion_task_force /assets/publications_1997_to_2006/making_transport_200 3. pdf. 2003; 67.

[13] Riverson J, Gaviria J, Thriscutt S. Rural roads in sub-Saharan Africa. World Bank Technical Paper. 1991; 141.

[14] Tighe D, Roads and Poverty Reduction. International Seminar on Rural Road Transport to on the 15-16 May 2002 in Siem Reap. Cambodia: www.ruralroads.org, 2006.

[15] IMF. (2012). Ghana: Poverty Reduction Strategy Paper. Washington, D.C.: International Monetary Fund (IMF).

[16] Doczi J, Dorr T, Mason N, Scott A. The post-2015 delivery of universal and sustainable access to infrastructure services. Overseas Development Institute, London, UK. 2013 Jun.

[17] Canning D, Pedroni P. Infrastructure and long-run economic growth. Center for Analytical Economics working paper. 1999 Dec; 99(09).

[18] Duncan I, Policy S. Transport interventions-towards value for money over time.

[19] Edmonds G. Wasted time: the price of poor access. Geneva: ILO; 1998.

[20] Ellis SD. Key issues in rural transport in developing countries. Crowthorne: Transport Research Laboratory; 1997.

[21] Gauthier A, Hook W. Tapping the market for quality bicycles in Africa. Sustainable Transport. 2005(17).

[22] Porter G. Intermediate means of transport: a review paper 
with special reference to Ghana, 2002.

[23] Okoth NJ. Cycle-based transport services in Kenya: the Ngware Bicycle Transporters Youth Group. Schopfheim: Schorrell Analysis. 2005.

[24] Guyer JI. An African niche economy: farming to feed Ibadan, 1968-88. Edinburgh University Press; 1997.

[25] Yunusa MB. Not farms alone: a study of rural livelihoods in the Middle Belt of Nigeria, 1999.

[26] Fasakin JO. Some factors affecting daily profits of commercial motorcycles in Akure, Nigeria. Transport Policy. 2001 Jan 1; 8(1):63-9.
[27] Porter G, Lyon F. Groups as a means or an end? Social capital and the promotion of cooperation in Ghana. Environment and Planning D: Society and Space. 2006 Apr; 24(2):249-62.

[28] Cresswell J. Research design. Sage Publications; 2014.

[29] Bogner, A Bogner A, Menz W. The theory-generating expert interview: epistemological interest, forms of knowledge, interaction. Interviewing experts 2009 (pp. 43-80). Palgrave Macmillan, London.

[30] Sarkar AK, Ghosh D. Meeting the accessibility needs of rural poor. IASSI Quarterly. 2000 Apr; 18(4):1-5. 